\title{
LENGUAJE Y VERDAD. SOBRE LA RELACIÓN ENTRE RETÓRICA Y FILOSOFÍA EN HANS-GEORG GADAMER*
}

\author{
Mirko WISCHKE \\ Universidad Palacky
}

\begin{abstract}
RESUMEN. La filosofía práctica, la retórica y la hermenéutica constituyen en la obra de Gadamer una constelación central y al mismo tiempo problemática. Si la lingüisticidad (Sprachlichkeit) y la relación con el lenguaje (Sprachbezogenbeit) de toda comprensión tienen para la hermenéutica la fuerza de acuñar una teoría, con ello se tematizan, por otra parte, los motivos que Gadamer encuentra para romper el estrecho concepto de hermenéutica como arte de la comprensión de textos. Sin embargo, su comprensión de la hermenéutica como filosofía práctica sólo se puede reconstruir mediante un eslabón intermedio: la rehabilitación de la retórica. La tesis de las siguientes reflexiones es que la rehabilitación de la retórica es la base para la comprensión gadameriana de la hermenéutica en tanto que filosofía práctica. Mi exposición reposa en la asunción de que la concepción de Gadamer de la hermenéutica como filosofía práctica se apoya sobre la corrección de una idea de la retórica cuyo sentido de productividad histórica (wirkungsgeschichtlich) se ha visto reducido, y en que el debate de la relación entre la ética y la hermenéutica nos confronta con un problema que sigue sin resolverse. Pero ¿qué es la retórica, si no es un arte de la persuasión, como Platón parece definir en sus diálogos?
\end{abstract}

La filosofía práctica, la retórica y la hermenéutica forman en la obra de Gadamer una constelación central y problemática: central, porque pone de relieve las líneas básicas de la hermenéutica de Gadamer, y problemática, porque tanto la concepción gadameriana de la retórica como lo que une la filosofía práctica, la

* Traducción del original alemán a cargo de Albiol Sunyer i Taxxer. 
retórica y la hermenéutica necesitan ser explicitados. Así, en la conferencia «El problema de la conciencia histórica" (1958), que tiene por tema la relación de la filosofía práctica y la retórica, se afirma que la filosofía práctica ofrece una «justificación científica a la racionalidad práctica que permite la convivencia entre los seres humanos, y que está presente en la tradición de la retórica a lo largo de los siglos»'. En esta breve exposición se ponen en conexión varias cuestiones, planteadas desde una perspectiva filosófico-histórica. Primeramente se revisa la tesis de que la tradición de la racionalidad práctica se forma en la retórica; en segundo lugar, se cuestiona la idea de que la justificación científica de esta forma de racionalidad se cumpla en la filosofía práctica; y, en tercer lugar, se muestra cómo la relación entre filosofía práctica y hermenéutica sigue sin ser resuelta. Esta relación se explica en el ensayo "Hermenéutica como filosofía práctica" (1972) como una coincidencia de la hermenéutica y la filosofía práctica. Gadamer también se refiere ocasionalmente a un "parentesco de vecindad" ${ }^{2}$, pero subraya una y otra vez la coincidencia de la hermenéutica y la filosofía práctica: «La hermenéutica es filosofía, $y$, en tanto que filosofía, filosofía práctica ${ }^{3}$. Pero también destaca que la hermenéutica está emparentada con la filosofía práctica porque su "objeto", en un contexto de situaciones cambiantes, tiene que precisarse de nuevo en cada caso, y porque su conocimiento se aplica una y otra vez a la situación concreta de cada práctica e interpretación ${ }^{4}$. Gadamer da una indicación precisa para resolver la cuestión de en qué medida coinciden la hermenéutica y la filosofía práctica cuando afirma que su concepción de una hermenéutica filosófica se remite a su "fundamento del mundo de la vida», a diferencia de la hermenéutica "tradicional», que se concentra en la comprensión de textos. Por otra parte, la exposición de esta remisión no deja de presentar problemas. Porque ¿qué entiende Gadamer por fundamento de la hermenéutica en el mundo de la vida? Y sobre todo: ¿en qué contexto explicativo se halla el fundamento de la hermenéutica en el mundo de la vida respecto a la filosofía práctica y la retórica?

Gadamer retoma la reflexión sobre la autointerpretación del Dasein procedente del proyecto heideggeriano de una hermenéutica de la facticidad, reflexión

1 Hans-Georg GADAMER, «Einleirung» (1975), en: Das Problem des historischen Bewusstseins (1958), Tubinga, 2001, 5.

${ }^{2}$ Id., "Hermeneutik als praktische Philosophie", en: Vernunft im Zeitalter der Wissenschaft, Fráncfort del Meno, 1991, 78-109, aquí: 89, 105.

${ }^{3}$ Id., 108.

${ }^{4}$ Id., 84. 
que pone como base de su comprensión del lenguaje como fundamental "condición del ser de todas las acciones y creaciones humanas". Esto explica por qué Gadamer puede afirmar que la hermenéutica no solamente tiene que ver con la interpretación de textos clásicos y su comprensión (Begrifflichkeit). Si la lingüisticidad (Sprachlichkeit) y la relación con el lenguaje (Sprachbezogenheit) de toda comprensión tienen para la hermenéutica la fuerza de acuñar una teoría, con ello se tematizan, por otra parte, los motivos que Gadamer encuentra para romper el estrecho concepto de hermenéutica como arte de la comprensión de textos. Sin embargo, su concepción de la hermenéutica como filosofía práctica sólo se puede reconstruir mediante un paso intermedio, que en lo sucesivo se definirá como una rehabilitación de la retórica. La tesis que subyace tras las siguientes reflexiones es que la retórica rehabilitada constituye el fundamento de la concepción de Gadamer de la filosofía práctica. En este sentido, sólo me referiré a la concepción gadameriana de la filosofía práctica en la medida en se requiera para esclarecer la relación sistemática entre hermenéutica y retórica. Pero ¿̨cuál es esta concepción de la retórica? ¿Qué es la retórica, si no es un arte de la persuasión, como Platón parece exponer en sus diálogos?

\section{1. ¿Qué es retórica originariamente?}

Para comprender la constelación de problemas que se esconde detrás de estas preguntas en su diversidad de niveles, no basta con dar expresión a la sospecha de que la rehabilitación hermenéutica de la retórica hace imposible una distinción entre lo verdadero y lo falso, entre opinión y ciencia ${ }^{6}$. Una tal sospecha se basa en la hipótesis de que la retórica se puede definir como un arte de la persuasión, aun cuando el oyente, convencido por la elocuencia del orador, no llegue a entender claramente lo dicho. Considerada desde este punto de vista, la retórica es el arte de demostrar todo y su contrario. Esta práctica, por tanto, apenas tiene algo que ver con la cuestión de la verdad.

Gadamer conoce a fondo esta concepción tradicional de la retórica. Sin embargo, esta interpretación no supone una seria objeción a la retórica, porque para

5 Id., "Historik und Sprache» (1987), Gesammelte Werke (a continuación abreviado como GW), Bd. 10, 324-330, aqui: 328.

"Véase Gianni VATTIMO, “Weltverstehen-Weltverändern", en: «Sein, das verstanden werden kann, ist Sprachen. Hommage an Hans-Georg Gadamer, Fráncfort del Meno, 2002, 50-60, aquí: 54. 
Gadamer es la expresión de una concepción reduccionista de la misma, que equipara el arte de la persuasión a una imposición. Gadamer deduce de ello que si se puede demostrar que la persuasión retórica no se puede equiparar a una imposición por la fuerza, se debería corregir la concepción de una retórica puramente instrumental. Pero ¿qué se puede alegar en contra de un concepto demasiado estrecho de la retórica? ¿Qué entiende Gadamer por concepto «amplio» de la retórica?

En su rechazo del concepto reduccionista de la retórica, Gadamer acude a Platón, que parece dar la razón a aquellos que postulan que el arte persuasivo de la retórica y la imposición forzosa apenas se diferencian. En primera instancia, los aspectos de la descripción platónica de la retórica citados por Gadamer parecen confirmar más bien las tesis sobre la retórica de aquellos a quienes el filósofo alemán critica. Platón señala que la retórica convence pero no ofrece una explicación sólida, y que se caracteriza por las bellas palabras del arte de la oratoria. El criterio del éxito de un tal discurso es la persuasión o el convencimiento del oyente que enjuicia el estado de cosas expuesto. Pero para Gadamer esto es menos un argumento a favor que un argumento en contra del concepto reduccionista de la retórica. La singularidad del retórico, a saber, su voluntad de persuadir a sus oyentes de que acepten lo que no puede probar, sirve a Gadamer de argumento contra la concepción instrumental de la retórica. Incluso cuando el retórico intenta por todos los medios dar credibilidad a su exposición, no está en condiciones de probar su veracidad como lo haría un matemático. Sin la certidumbre de la fórmula matemática, el retórico no es capaz de obligar a sus oyentes a creer en su discurso. La tesis de Gadamer según la cual la retórica se puede definir negativamente como el arte del convencer sin aportar pruebas, se apoya en Platón, para quien el retórico intenta demostrar algo cuando a fin de cuentas sólo puede persuadir. Convencido de la evidencia de sus convicciones, el orador busca la aprobación de sus oyentes en la medida en que intenta demostrar la veracidad de su opinión sin disponer de medios matemáticos de comparación y evidencia. La aprobación de la audiencia que escucha la exposición del orador es un proceso que no incluye razones en pro y en contra. El discurso puede ilustrar al oyente sin que éste haya emitido un juicio sobre aquél. Cuando el orador no puede influir mediante pruebas claras sobre la forma de pensar crítica de sus oyentes, la imposición de una afirmación no es plausible. Gadamer invalida la crítica a la retórica según la cual un discurso creíble y elocuente del orador puede impedir que la audiencia se haga un juicio propio, en la medida en que cuestio- 
na cómo se puede forzar la persuasión. Aun cuando al oyente le parezca evidente lo expuesto, ello no ha de ser necesariamente el resultado de lo escuchado: también puede deberse a la reconstrucción crítica y la comprensión reflexiva de lo expuesto. Cabe responder entonces a la cuestión de en qué medida la retórica puede dar validez a lo verdadero mediante el convencimiento. Hobbes ya había indicado que la retórica "está muy alejada del verdadero conocimiento de las cosas", ya que su objetivo no es la instrucción de la verdad, sino la persuasión de la verdad, o de lo que se considera verdadero ${ }^{7}$. Pero como ha demostrado Blumenberg, la antítesis de verdad y efecto (Wirkung) que se podría leer en Hobbes es superficial, ya que el efecto retórico no es una "alternativa a una opinión que también se podría tener, sino a la evidencia que se puede no tener, o no tener aún [...] ${ }^{8}$. En este sentido, no hay que considerar la retórica como una solución en caso de emergencia, ya que la evidencia del saber que se expone de manera persuasiva depende de la no contradicción de lo expuesto, que hay que distinguir claramente de la provisionalidad de los resultados del saber científico.

Si aceptamos que el resultado de la persuasión puede ser su revocación, Gadamer consecuentemente rechaza por infundado que haya un automatismo de la persuasión y de la imposición. Por tanto, se puede defender que la retórica implica la renuncia a la imposición. A esta reflexión va unido un problema que presenta también la persuasión: el problema de la comunicabilidad (Mittelbarkeit), que está implícito en Gadamer. La retórica sería un instrumento que permite descubrir la evidencia del estado de cosas (Sachverhalt) que se cree tener del todo o de forma aún incompleta. A Gadamer no le preocupa cómo se puede comunicar algo de forma que otros consideren plausible lo escuchado. Una reflexión de Kant, que añade un elemento importante a las anteriores reflexiones sobre la retórica, servirá para exponer lo que le interesa a Gadamer.

Kant considera que la verdadera dificultad de la retórica es la cuestión de la comunicabilidad. Su definición de la retórica como una ciencia acrítica de la apariencia no le impide observar que la persuasión de la retórica es una forma de tener por verdadero (Fürwahrhalten), que también puede aparecer en forma de convicción (Überzeugung). Para Kant el fundamento más profundo de la persua-

7 Thomas HobBes, Grundaüge der Philosophie. Dritter Teil: Lehre vom Bürger (De Cive), versión alemana del inglés por Max Frischeisen-Köhler, Leipzig, 1949, X, 11 y 12.

${ }^{8}$ Hans BlumenberG, Wirklichkeiten in denen wir leben, Stuttgart, 1999, 111. 
sión es el tener por verdadero; hondamente persuadido de la verdad de sus pensamientos, el orador busca a otros para comunicarles su parecer, sin que se le pueda atribuir la intención de querer obligarles a aceptar su opinión. Como generalmente no se le puede reprochar esta intención, para Kant la motivación primordial de la comunicación no es tanto tratar de imponer como resolver la cuestión de saber hasta qué punto las opiniones consideradas verdaderas se pueden comunicar de forma que también sean reconocidas como verdaderas por otros. Kant es consciente de que la persuasión apenas puede distinguirse del convencimiento, a no ser que las razones que alguien expone para convencerse a sí mismo tengan el mismo efecto en otras personas; sólo en este último caso Kant puede afirmar definitivamente que se trata de persuasión. Si una opinión es rechazada repetidas veces por otros, el juicio mediante el cual una persona llega al convencimiento tiene tan sólo una validez privada (Privatgültigkeit): «La piedra de toque del tener por verdadero, que manifiesta si se trata de convencimiento o simplemente de persuasión, es [...] la posibilidad de comunicar lo mismo y hallar un tener por verdadero que sea válido para la razón de todo ser humano" ${ }^{9}$ La comunicabilidad y la plausibilidad de lo comunicado son los criterios que deciden si el tener por verdadero permanece dentro de los límites de la validez privada, o rompe estos límites. La persuasión retórica, que no puede aportar la prueba estricta de su veracidad, se cumple en una comunicación lingüística que tiene que ser evidente para los oyentes cuando éstos estén convencidos de lo comunicado. La definición kantiana de la relación de la comunicación convincente y la objetividad (Sachbezug) como "tener por verdadero" permite concluir que quiere llamar la atención sobre un problema ambivalente de la retórica.

Este problema es ambivalente porque cuando el orador quiere convencer a sus oyentes de que su exposición del estado de cosas es verdadera y pertinente, debe esforzarse en exponer sus ejemplos y aclaraciones de la forma más comprensible, concebible y plausible posible. El que sus exposiciones se correspondan con el estado de cosas es otra cuestión. También es completamente concebible que se impongan "falsas" concepciones, si parecen exponer de forma comprensible estados de cosas que antes eran completamente inexplicables. Igualmente, una afirmación puede no ser aceptada una y otra vez con independencia de si es verdadera o falsa. Podemos responder con Kant a la pregunta de si una

\footnotetext{
9 Immanuel KanT, Vorlesung über Encyclopädie und Logik, Berlín 1961, 688.
} 
forma de contemplar un problema puede convertirse en algo aceptado por todos: sólo cuando lo tenido por verdadero es aceptado más allá de los límites de la validez privada. Quiero llamar especialmente la atención sobre este peligro, porque en la perspectiva de Gadamer sólo parece darse en el horizonte de un concepto reducccionista de la hermenéutica.

El ejemplo del Gorgias de Platón, citado a menudo para ejemplificar la ceguera de la retórica respecto a la verdad, es interpretado por Gadamer de otra manera: cuando Gorgias convence a alguien de una tesis y de su antítesis, no quiere mostrar que las dos tesis sean demostrables. Su oratoria demuestra más bien que la fuerza del convencimiento no se debe confundir con la demostración. Gadamer deduce de esta reflexión que la tesis según la cual la retórica convence per se de lo falso es una simple suposición. Del arte oratorio de la retórica no se desprende que parta exclusivamente de falsos supuestos, ni que la retórica esté en condiciones de extorsionar la aprobación de los otros. Lo que Gadamer quiere destacar es una posibilidad que niega el prejuicio tradicional contra la retórica: que no se puede descartar que la retórica comunique algo verdadero.

Pero aunque sea cierto que no se puede mantener la equiparación del persuadir y del forzar, ni sea cierto que la persuasión sea indiferente a la verdad, queda sin responder la pregunta de cómo Gadamer quiere determinar la relación de intensidad de lo evidente con el grado de verdad. Al igual que los críticos de la retórica, que están demasiado atentos a la objeción de que la retórica utiliza cualquier argumento créble, y que no están dispuestos a reconocer que con ello no se dice nada sobre la verdad o falsedad de los argumentos, Gadamer, cuando otorga a la retórica el derecho a la verdad, parece suponer sin confesarlo que la retórica principalmente comunica la verdad.

La validez de este argumento se puede poner en duda si consideramos que la retórica puede proceder de la verdad, pero no necesariamente, lo que no quiere decir que aquella pueda proporcionarle a ésta su derecho mediante un discurso convincente. Los motivos de Gadamer para suponer que la retórica consiste principalmente en la comunicación de algo verdadero son poco claros, porque en la descripción platónica el orador ante todo quiere entusiasmar a los oyentes mediante una demostración convincente de sus propios argumentos. Afirmar que la retórica procede principalmente de la verdad significa atribuirle algo que los maestros del arte oratorio descritos por Platón normalmente no proporcionan, ya que 
consiguen la aprobación de su audiencia simplemente mediante su arte, que en sí mismo no dice nada de la verdad o falsedad del estado de cosas expuesto en un bello discurso. No tener en cuenta estas reflexiones supone infravalorar la ambivalencia que señala Kant en su descripción del tener por verdadero (Fübrwahrhalten). Suponiendo que Gadamer tiene en cuenta esta ambivalencia, cabe preguntase cómo reacciona ante ella.

En la lectura gadameriana de Platón se halla una indicación que permite concluir que la ambivalencia que Kant había observado en la retórica debe ser neutralizada ontológicamente en el problema de la comunicación linguística. Cuando Gadamer alude al Fedro, donde Sócrates defiende el arte de la oratoria porque con ella se puede transmitir al otro el reconocimiento de lo que es verdadero y correcto, cabe preguntarse si Gadamer piensa realmente en la retórica o en la comunicación lingüística de lo tenido por verdadero que se realiza en la retórica. Muchas observaciones de Gadamer sobre la dialéctica del diálogo ponen el acento en este último aspecto.

Afirmar que el retórico en su discurso sólo quiere defender aquello de lo que está firmemente convencido, supone atribuirle una rectitud ética que se puede describir con el concepto kantiano de tener por verdadero y el desamparo de sólo poder comunicar lo que el retórico tiene por verdadero con palabras elocuentes. En el plano de las consideraciones puramente éticas, la observación de Gadamer de que los seres inmorales también se esfuerzan por entenderse es contradictoria, ya que parece suponer una buena voluntad que no se tematiza expresamente. La observación de Gadamer aparece bajo otra luz considerada en el plano de la comunicación lingüistica. La voluntad y disposición para el entendimiento que Gadamer supone en cada diálogo se desprenden necesariamente de la premisa de que todo lenguaje es un intercambio de discurso y respuesta.

La comunicación lingüística tiene una especial relevancia en otro aspecto, en la medida en que con ella se precisa lo que hay que entender por retroceso al fundamento del mundo de la vida de la hermenéutica. La operación de la comunicación linguística es un fenómeno del discurso dialógico, mediante el cual alguien debe ser convencido de lo que otros consideran verdadero - un elemento del hablar uno con otro y del entendimiento mutuo que la retórica contempla con especial atención-. Estar en una conversación uno con otro implica para Gadamer un intercambio de convicciones cuya exteriorización puede obtener tanto 
aprobación y comprensión como crítica y oposición. Pero ¿qué lugar ocupa en la retórica el intercambio discursivo (Wechselrede) del que habla Humboldt?

La pretensión de verdad que acompaña a las manifestaciones de cuya verdad otras personas deben ser convencidas se muestra en el esfuerzo por ser plausible. La retórica no es ninguna excepción. A falta de una demostración comparable a la ofrecida por las matemáticas, en el proceso de la persuasión no se pueden dar exposiciones verdaderas o falsas en sentido estricto, sino en todo caso convincentes o menos convincentes, que no son ni indudables ni irrecusables o seguras. Todas las comunicaciones lingüísticas de aquello de lo que uno está convencido son en todo caso un esfuerzo por hacer que algo sea creíble, un intento que nunca termina definitivamente. Esta reflexión es imprescindible para entender el concepto gadameriano de la verdad en el plano de la comunicación lingüística.

La simple evidencia interna del comprender es la que decide, según Gadamer, qué exposición lingüística aparece como persuasiva y convincente. La evidencia de la comprensión, la sorprendente comprensión de algo que antes era vago, oscuro y extraño, reposa en una suposición que hay que entender como más fundamental que la comprensión ética. La rehabilitación hermenéutica de la retórica a la que procede Gadamer se apoya en dos momentos, que son la característica fundamental del hablar uno con otro: el percibir (Vernehmen) y el manifestar (Verlautbaren). El que intentemos comprendernos no es para Gadamer un fenómeno originariamente moral, ni necesita condiciones ético-morales de las que dependa la comprensión.

\section{2. ¿Una hermenéutica sin ética?}

Gadamer aprendió de Natorp que el lenguaje y la percepción deben ser pensados conjuntamente. Según Natorp, la percepción es la responsable de la manifestación del lenguaje: donde no hay percepción tampoco existe ningún hablar. Natorp parte de la premisa de que en las comunicaciones lingüísticas la percepción y la comprensión en la escucha deben considerarse igualmente originarias a lo dicho. Gadamer sigue el pensamiento de su maestro neokantiano cuando fundamenta el lenguaje en el habla y la escucha mutua, que considera igualmente originarios. Este punto de vista es muy ilustrativo para entender la retórica según Gadamer. Si la tarea de la retórica consiste en dar a entender y comunicar una 
opinión sin poder demostrarla, la exposición retórica reposa menos en una argumentación lógica que en la capacidad de convencimiento (Überzeugungskraft) humana, lo cual implica una apertura al otro, y a lo que dice. La tesis de Gadamer según la cual toda ética es retórica ${ }^{10}$ no sólo generaliza el hecho de que la condición de la retórica presupone la escucha interesada del estado de cosas expuesto en la opinión del otro. Para Gadamer, el arte del discurso convincente radica en nuestra capacidad innata de entendernos unos con otros, y de "manifestar en el diálogo aquello de lo que nosotros mismos estamos convencidos, y que, sin embargo, no podría mostrarse como tal en el modo habitual de la demostración" ". Esta reflexión parte de la idea de que en la consumación del lenguaje se forman aquellas formas específicas de la convivencia sin las cuales ninguna ética sería concebible: entendimiento, comprensión mutua y respeto.

A primera vista esta afirmación parece coincidir con Vattimo, que afirma que en la hermenéutica de Gadamer «los criterios en la búsqueda de la palabra justa, los criterios de diferenciación entre lo verdadero y lo falso, así como de una interpretación acertada o desacertada, están en el lenguaje mismo» ${ }^{12}$. Pero ¿qué significa «en el lenguaje mismo"? La cuestión es determinar si al lenguaje se le pueden atribuir no sólo los medios de la comunicabilidad, sino también la capacidad de discriminar lo verdadero de lo falso. El problema se puede formular con la siguiente pregunta: ¿se puede realmente concebir la comprensión expresada en el lenguaje del diálogo sin parámetros éticos? Si la comprensión respecto a lo que dicen otros ya existe en el lenguaje como un fenómeno premoral, ¿̨cómo se explica que los seres humanos no acepten el consejo bienintencionado de otras personas, y no escuchen otras opiniones que aparecen en la conversación?

Para despejar cualquier duda, no es mi intención reducir la rehabilitación gadameriana de la retórica a una dimensión puramente ética; de ser así, habría renunciado a mencionar las reflexiones de Gadamer alrededor de la tesis de que la ética es retórica. Es indiscutible que escuchar el discurso de otro es una característica del lenguaje. Pero la cuestión es saber si esto es pensable sin un mínimo de condiciones éticas previas.

${ }^{10}$ Hans-Georg GADAMER, Die Lektion des Jahrhunderts. Ein philosophischer Dialog mit Riccardo Dottori, Münster, 2002, 59.

11 Id., 57.

${ }^{12}$ Gianni VatTimo, Weltverstehen-Weltverändern, op. cit., 55. 
Plantear esta cuestión no tiene sentido si se argumenta con Gadamer y Natorp que la palabra siempre está dirigida a otro, y que por tanto lleva en ella de forma implícita la exigencia de una respuesta. No dirigimos la palabra a alguien sin esperar que entienda lo que decimos, y al ser entendidos podemos suponer con razón que nos va a responder. La comprensión de lo hablado y de lo escuchado no presupone necesariamente una base ética entre el hablante y el oyente. Gadamer tiene buenas razones para pensar que el diálogo no tiene condiciones previas de tipo ético. Pero ve resuelto el misterio de la conversación, que fue el centro de la problemática de la dialéctica del diálogo de Platón, en la constitución del lenguaje como la realización del acuerdo (Verständigung) y apertura de mundo (Welterschließung). La voluntad y la disposición para el acuerdo, condiciones previas según Gadamer de toda conversación, se derivan necesariamente de la constitución lingüística (sprachliche Verfasstheit) de nuestra forma de vida.

Gadamer coincide con Natorp en que Platón fue el primero en reconocer la dimensión de la comunicación lingüística del diálogo, en la medida en que identifica los momentos de la conversación consigo mismo (Sich-Unterreden), del intercambio mutuo y del comprenderse consigo mismo y con otros presentes en el "dia-logos» (Natorp). Para Gadamer, el habla "no sólo es la sucesión de una estructura de palabras portadoras de sentido"; es algo que «se dice a alguien, y del tono depende la forma convincente y no convincente del discurso» ${ }^{13}$. Lo que Gadamer no menciona es que sin una determinada dosis de buena voluntad una comunicación lingüística apenas sería considerada de interés. La atención puesta en la escucha de un estado de cosas quedaría muy menguada si el oyente siguiese la explicación de lo expuesto con indiferencia — una condición previa que tiene implicaciones éticas-. Este aspecto se echa de menos en el razonamiento de Vattimo.

Sin duda alguna, la tesis de Vattimo se basa en la equiparación del ser y del lenguaje que se hace en Verdad y Método, según la cual el lenguaje es el ser que puede ser comprendido. Sin embargo, la observación de Vattimo es equívoca, porque considera las reflexiones de Gadamer sobre el lenguaje bajo un solo aspecto: el de su potencial cognitivo. Vattimo no pretende que para Gadamer la existencia de una palabra se pueda equiparar a la existencia de lo señalado por ella,

13 Hans-Georg GADAMER, "Die Philosophie und ihre Geschichte" (1998), en: Hermeneutische Entwürfe: Vorträge und Auffätze, Tubinga, 2000, 69-96, aquí: 205. 
pero pasa por alto que la renuncia de Gadamer a una ontología de lo presente (Vorhandene) reconoce una diferenciación entre pensar, lenguaje y ser, para poder descubrir fenomenológicamente las operaciones de apropiaciones (Aneignungsvollzüge) de las tradiciones. Para Gadamer las cosas no están realmente ni en el entendimiento (Verstehen) ni en el lenguaje. Fue en Marburgo donde Gadamer conoció la teoría de Natorp del "milagro originario de la palabra", que no hay que entender como una "simple representación", sino como un "pronunciarse originario" (ursprüngliches Sichausprechen) ${ }^{14}$. El auténtico problema no es lo cerca de la realidad que se puedan llevar o no las cosas al lenguaje: "Pensar depende del fundamento del lenguaje, en la medida en que el lenguaje no es un mero sistema de signos para la transmisión comunicativa de informaciones. El conocimiento previo de lo denominable antes de toda denominación no es asunto del lenguaje. En la relación lingüística del mundo (sprachlichen Weltbezug) lo hablado se articula primeramente mediante la constitución lingüística de nuestro seren-el-mundo (In-der-Welt-Sein)" ${ }^{15}$. La constitución lingüística (Sprachverfasstheit) comprende más aspectos que los de la apertura del mundo (Welterschießsung) y el conocimiento: "La 'verdad" de la palabra no reside [...] en su corrección, en su correcta adecuación a la cosa. Reside en su completa espiritualidad, es decir, en poner al descubierto el sentido de la palabra en el sonido. En este sentido, todas las palabras son 'verdaderas', es decir, su ser se abre en su significado, mientras que las imágenes (Abbildungen) sólo se parecen más o menos, y, por tanto, [...] son relativamente adecuadas" ${ }^{16}$. Como las palabras, el lenguaje tampoco posee una real significación cognitiva. Cuando Vattimo afirma, sin embargo, que los criterios de verdadero y falso incluyen la constitución lingüística del mundo (Weltverfasstheit), es lícito sospechar que lee a Gadamer a partir de Heidegger.

Como es sabido, en su interpretación de la poesía de Stefan George Das Wort («La palabra»), Heidegger afirma que la poesía tiene como fundamento el pensamiento, que una cosa sólo está allí donde se conserva la palabra. Gadamer también podría haber concebido el lenguaje de esta manera, si hubiera considerado el «imperar» (Walten) del lenguaje como un decir (Sagen) que deja aparecer lo ente en su "es» (es ist). Heidegger considera que el lenguaje deja aparecer la palabra como lo ente (Seiendes), mientras que Gadamer subraya que «la verdad

14 Paul NatorP, Philosophische Systematik, Hamburgo, 2000, 33.

15 Hans-Georg GADAMER, "Hegel und Heidegger" (1971), GW 3, 87-101, aquí: 101.

16 fd., Wabrheit und Methode, loc. cit., 415. 
que mora en el lógos no es la de la simple percepción [...], no es un dejar aparecer del ser, sino que siempre pone el ser en un punto de vista, le concede y le promete algo». No es "la palabra (ónoma), sino el lógos el portador de la verdad (y también de la falsedad)" ${ }^{17}$. Si las palabras no tienen una verdadera dimensión cognitiva, Gadamer consecuentemente no ve en la hermenéutica la capacidad intuitiva (Verständnis) para arrancar al olvido los conocimientos cristalizados en palabras y conceptos. Aun cuando Gadamer describe el lógos como la «esencia (Inbegriff) de los conocimientos (Einsichten) del hombre vertidos en lenguaje y enriquecidos en forma lingüística» ${ }^{18}$, la hipótesis de que la filosofía piensa radicalmente el lenguaje para liberar mediante una cuidadosa interrogación las sabidurías encerradas en él, se apoya en una base poco convincente. Sobre la base de las observaciones de Gadamer de que los conceptos «siempre se desarrollan a partir de la experiencia», que "articulan nuestra comprensión del mundo" y que "señalan el curso de la experiencia»", Vattimo parece querer decir que una característica de la hermenéutica gadameriana es la búsqueda de los síntomas (Merkmale) de lo verdadero y lo falso en el lenguaje mismo. Se trata de una aseveración muy imprecisa en su generalización, ya que el mismo Gadamer afirma que el cometido de la filosofía y de la hermenéutica no se cifra sólo en recuperar los segmentos de significado (Bedeutungssegmente) de los conceptos y su verdad (o falsedad).

\section{La función de conocimiento crítico de la retórica}

$\mathrm{El}$ que las palabras no tengan una real función cognitiva se relaciona con la concepción de Gadamer de que la retórica primariamente no tiene por función la comunicación de verdades evidentes, sino de lo que se tiene por verdadero. En la tradición filológica esta concepción tiene su propia productividad histórica (Wirkungsgeschichte), a la que va asociado especialmente el nombre de Friedrich Nietzsche.

Influido por el ensayo de Gustav Gerber «El lenguaje como arte» (1871, Vol. 1.), Nietzsche defiende la tesis de que la retórica no trata de la verdad, el conocimiento y la comprensión, sino de lo probable y de lo tenido por verdadero.

${ }^{17} \mathrm{Id} ., 416$.

18 fd., "Bürger zweier Welten» (1985), GW 10, 225-237, aquí: 227.

19 fd., "Kausalität in der Geschichte» (1968), GW 4, 107-116, aquí: 110. 
«La retórica no trata de saber, sino de lo que tenemos por verdadero en base a razones de las que no tenemos que rendir cuentas: su objeto es un "tener por verdadero habitual" (gewohntes)" ". Para Nietzsche la elección entre el simple tener por verdadero y el conocimiento real no es una alternativa, ya que no existe un conocimiento de la verdad propiamente dicho. El ser humano no puede conocer las cosas tal como son realmente - una dificultad que el ser humano combate con la apariencia, que no es una forma de ver superficial o inapropiada, sino la única realidad verdadera de las cosas-. Para Nietzsche, la apariencia no es una presencia de las cosas diferenciada de su «verdadero» ser. Su concepto de apariencia no se puede reducir al deseo de apariencia propio de una simplificación que necesitamos para orientarnos en el mundo. La apariencia tampoco es la expresión del anhelo (Sehnsucht) de salvación frente a un mundo de una crueldad y un sufrimiento inimaginables, como lo describe Nietzsche en El nacimiento de la tragedia.

La apariencia, que constituye la metaforicidad y el antropocentrismo del lenguaje, su forma artística y su fuerza creadora, sirve para la autoafirmación de los seres humanos en su forma más elemental: sólo en el lenguaje tiene el ser humano acceso al ser, cuya intuición originaria (Uranschauung) es el devenir; sin el lenguaje el hombre no se podría orientar en el mundo ni ponerlo a su disposición. El lenguaje no representa ni reproduce algo; lo que describe es simplemente la relación de las cosas con los seres humanos. La rehabilitación nietzscheana del problema de la apariencia retórica está ligada al descubrimiento de la dimensión epistemológico-crítica de la retórica, que combate la falsa apariencia de un objetivismo naïf. Una tal concepción recuerda las reservas de Gadamer respecto al objetivismo naif, que otorga a las palabras una correspondencia real con las cosas.

Los paralelos con las reflexiones de Gadamer sobre la retórica no acaban aquí. Otro punto en común: Nietzsche no entiende por retórica un arte de disciplina auxiliar para comunicar la verdad; por el contrario, la retórica debe provocar el asentimiento de otros a lo que nosotros tenemos por verdadero. Si otros confirman nuestro discurso, éste tiene entonces algo de convincente y plausible. El lenguaje, por tanto, no es monológico, porque siempre está dirigido a otros. Lo que se comunica tiene el objetivo de conseguir la aprobación de otros de lo que noso-

${ }^{20}$ Friedrich NIETZSCHE, Nachlass 1885-1887, Kritische Studienausgabe (= KSA), editado por Colli y M. Montinari, Múnich, 1988, Bd. 12, 103, 2 (84). 
tros tenemos por verdadero. El que quiera que se acepte lo que tiene por verdadero tendrá que recurrir a la virtualidad del lenguaje y a la capacidad evocadora de las palabras habladas. Según Gadamer y Nietzsche, la retórica se caracteriza por reivindicar estos dos elementos.

Resumiendo las anteriores consideraciones, se impone responder a las siguientes preguntas: ¿por qué el "ancho" concepto de retórica es hermenéuticamente tan interesante para Gadamer? ¿Es imprescindible la rehabilitación de la retórica para apoyar la tesis según la cual la comprensión es una comprensión otra (Andersverstehen), tal como se expone en Verdad y Método? ¿Qué une la retórica con la filosofía práctica y la hermenéutica? ¿Qué significado tiene el concepto gadameriano de retórica en la coincidencia de la hermenéutica y la filosofía práctica?

\section{4. ¿Hermenéutica sin retórica (rehabilitada)?}

Gadamer advierte en la retórica un modelo para la ilustración histórico-conceptual (begriffsgeschichtliche Aufklärung) que debe realizar la hermenéutica filosófica. Incluso si la "auténtica» retórica, la que supera la mera técnica del arte de la oratoria que buscaba Platón en el Gorgias, no muestra la cosa misma, sino que la representa a los oyentes tal y como la ve el orador, para Gadamer sigue estando guiada por la intención de convencer y persuadir de algo, cuando este algo, en su opinión, no se puede mostrar tan fácilmente. Gadamer destaca en la retórica su capacidad para reproducir la misma cosa de múltiples maneras, y en la tarea de la comprensión histórica del concepto ve la posibilidad de arrojar una nueva luz sobre el concepto filosófico, mostrando la experiencia originaria que está contenida en él. La tesis de Platón en Fedro 235b y 236b, según la cual para poder superar un discurso hablado o escrito debería poderse proporcionar al estado de cosas discutido un contenido diferente y mejor, la interpreta Gadamer en el sentido de dejar en libertad, con ayuda de la multivocidad de la palabra escrita, las diversas perspectivas sobre ese estado de cosas - y con ello poner a la vista el propio estado de cosas de la manera más adecuada posible-.

Platón se refiere también al siempre presente pâthos de los lógoi, esto es, el duro trance (Widerfahrnis) del pensamiento que se enreda en contradicciones. Gadamer no entiende este concepto exclusivamente de forma negativa, como una confusión de conceptos, percepciones, representaciones tradicionales y for- 
mas de pensamiento, como lo hace la ilustración griega bajo la modalidad del arte del discurso retórico y de la argumentación de los sofistas. Para Gadamer, Platón ha demostrado que el discurso retórico tiene una verdadera función filosófica: dirigir la atención a las relaciones «verdaderas» de las cosas en medio de la confusión de las formas de pensar y de las opiniones, para llevar adelante la interpretación del estado de cosas. Dado que no se puede eliminar de la conversación la confusión del conocimiento, definida por Platón como un duro trance siempre presente, resulta que ni el nombre ni la determinación conceptual, como tampoco la imagen evidente o el conocimiento, ofrecen para Gadamer una garantía de que a través de ellos se pueda acceder al conocimiento de la cosa misma en su verdadero ser. Sin embargo Platón los ha considerado, según Gadamer, desde un mismo punto de vista: son imprescindibles para conocer verdaderamente la cosa, aun cuando la cosa misma no se descubra destacada en forma de una palabra, concepto, ilustración (Veranschaulichung) o comprensión (Einsicht). Se trata de un aspecto que no habíamos mencionado en la exposición del concepto gadameriano de retórica.

Gadamer detecta la debilidad de los logoi en su tendencia intrínseca a realizar una inversión, de manera que una palabra, concepto, conocimiento o ilustración (Veranschaulichung) intentan hacerse valer a sí mismos, en lugar de desaparecer detrás de aquello que deben hacer presente: en cierto modo se plantan delante aquello que se muestra en ellos. Pero no solamente por ello tienden a hacerse vigentes en tanto que ellos mismos. Todos ellos tienen también un ser para sí mismos, mediante el cual se diferencian de lo que representan en tanto que cosa. Esta diferencia explica que la capacidad cognitiva del lenguaje postulada por Gadamer no consista en posibilitar el acceso a las cosas tal como son realmente. Para Gadamer, la palabra no remite a otra cosa de la misma manera que lo hace un signo. Con razón subraya Vattimo que la hermenéutica de Gadamer no quiere conocer las cosas como son realmente. Cuando concluye que «las cosas sólo son lo que son realmente en la interpretación y en el lenguajen" ${ }^{21}$, cabe preguntarse si esta definición describe adecuadamente la concepción de Gadamer del lenguaje. En realidad, esta tesis de Vattimo es más cercana a la concepción del lenguaje de Nietzsche que a la de Gadamer. Cuando el lenguaje mismo ya está interpretado, las cosas no pueden ser en el lenguaje lo que son realmen-

21 Gianni VATTIMO, "Weltverstehen-Weltverändern", op. cit., 53. 
te; más bien son nombradas en el lenguaje como son en cada caso en su contexto de significación. De esta manera, el significado de la experiencia registrada de forma lingüística no se puede agotar ni en la comprensión ni en lo comprendido. De la misma manera, un texto puede ser nuevamente interpretado en su esencia en un punto determinado mediante el reconocimiento (anámnesis). Esta observación se pone de relieve en la tesis de Gadamer sobre la debilidad de la escritura ${ }^{22}$.

Gadamer retoma de Platón la idea que todo texto tiene una carencia incurable: trata de sujetar lo que en su sujeción misma amenaza escurrirse. ¿Cómo puede el saber que Sócrates quiere descubrir mediante su arte del preguntar estar oculto en el fondo del alma, sin que aparentemente nosotros lo sepamos? Para Gadamer, esto se debe a la singularidad del lenguaje, que a menudo sólo puede expresar los estados de cosas que hay que comunicar en palabras inadecuadas. Existen dos razones de esta inadecuación: por un lado, a pesar de que tengan un significado concreto, las palabras ofrecen un abanico variable de interpretaciones, de manera que los estados de cosas que conocemos nunca se comunican de forma completa, es decir, en la totalidad de sus sentidos. Por otro lado, el lenguaje mismo ya aparece interpretado, ya que los estados de cosas que se transmiten de forma lingüística advienen al lenguaje mediante una determinada interpretación. Los estados de cosas que conocemos no sólo están a salvo en las palabras, sino que también están ocultos en ellas. Así pues, la afirmación de que las cosas sólo son lo que son verdaderamente en la interpretación y en el lenguaje, no es falsa, pero es una tosca generalización de la concepción de Gadamer, que ha tratado este tema de forma matizada. Para responder a la pregunta de cómo es posible otro modo de comprensión cuando queremos desvelar un sentido nuevo y extraño de unas mismas palabras, Gadamer responde: mediante el «volumen del lenguaje, que se enriquece gracias a la multiplicidad de sentidos y de posiciones que tienen y conjugan las palabras ${ }^{23}$. Sólo la posición de la palabra en el contexto del discurso mengua su ambigüedad, sin eliminarla. La palabra que interpreta acertadamente el sentido del discurso no sólo lo lleva al lenguaje, sino que también representa provisionalmente el sentido. Si el lenguaje es el fundamento ontológico a partir del cual se desarrolla la capacidad mayéutica del diálogo, la

22 Véase Mirko WISCHKE, Die Schwäche der Schrift. Zur philosophischen Hermeneutik HansGeorg Gadamers, Weimar-Colonia, 2001.

${ }^{23}$ Hans-Georg GaDAMER, "Heidegger und das Ende der Philosophie», op. cit., 202. 
tesis según la cual la ética es en su esencia retórica parece aceptable, aunque es problemática.

Como hemos visto, la voluntad y la disponibilidad para la comprensión que Gadamer supone en todo diálogo se desprenden necesariamente de la constitución (Verfasstheit) linguística de nuestra forma de vida. Se puede decir que la ética en cierta medida está fundamentada antropológicamente en la hermenéutica de Gadamer. La tesis de Gadamer según la cual los seres inmorales también quieren comprender es convincente en el plano de la filosofía hermenéutica. En el lenguaje conocemos estados de cosas cuyo conocimiento no supone ningún posicionamiento ético. Los "seres inmorales" se entienden mutuamente, porque el mundo en que viven está constituido lingüísticamente. Frente a esto, la tesis de Gadamer en el plano de la filosofía hermenéutica se pone la siguiente objeción: una comprensión interna del intérprete presupone querer llegar a una auténtica conversación. Para que existan las condiciones de un auténtico intercambio de ideas con el texto sin la corrección de la conversación oral no basta con mostrar una buena voluntad para comprender. La comparación del carácter lingüístico de la tradición que de nuevo vuelve al lenguaje (Zur-Sprache-Kommens) mediante la comprensión, con el carácter lingüístico de la experiencia humana del mundo, no tiene en cuenta que el diálogo, sin una cierta dosis de buena voluntad, no puede desarrollar su cualidad mayéutica.

Los anteriores razonamientos sobre la ética y hermenéutica parecen habernos alejado bastante de nuestra interrogación original. Pero las apariencias engañan; con la ayuda de estas reflexiones se puede plantear una pregunta que ya estaba presente en segundo plano cuando se trataba la cuestión de la concepción que tiene Gadamer del lenguaje: si Gadamer recurre a la retórica para algo que al fin y al cabo también realiza el lenguaje. ¿ No está constituido el lenguaje de tal forma que debido a la variedad de sentidos de la palabra hablada se "provoca una continua confusión de nuestro conocimienton? ${ }^{24}$ Si la singularidad del lenguaje es poder expresar estados de cosas en palabras a menudo inadecuadas, de manera que siempre hay que decir algo sobre ellos para apreciarlos en su complejidad y distinción, ¿cuál es el cometido de la retórica? ¿Necesita la hermenéutica de Gadamer, fundada sobre la concepción de una ontología del lenguaje, una retórica rehabilitada?

${ }^{24}$ Hans-Georg GADAMER, «Begriffsgeschichte als Philosophie» (1970), GW 2, 77-91, aqui: 79. 
Para Platón un discurso hábil se convierte en vacía sofística cuando no posee un contenido apropiado. Gadamer le da la vuelta a este razonamiento de manera muy típica en él: cuando debe despertar la palabra "muerta» del texto al lenguaje vivo, la hermenéutica debe contribuir a la elocuencia del discurso fijado en el texto. Esta inversión (Umkehrung) no desvela de forma precisa cómo hay que entender la elocuencia, si no es en el contexto de la afirmación de Platón de que el texto por sí mismo no produce sabiduría. De ello se desprende para la hermenéutica: cuando la interpretación tiene el cometido de exponer de forma comprensible un texto, debe ser algo más y algo otro que el texto interpretado. En la medida en que la hermenéutica hace despertar a la vida la palabra rígida, transmite el lenguaje del texto en el lenguaje correspondiente de la interpretación, que pretende explicitar una determinada comprensión del texto - y que no deja aparecer las cosas como son "realmente»-. En caso de que el trabajo hermenéutico se agotase en este aspecto, sería poco probable que la concepción de Gadamer de la hermenéutica necesitase una retórica rehabilitada como condición previa para la fundamentación y explicación de la tesis de la comprensión como comprensión otra (Andersverstehen).

Pero ¿hasta qué punto contribuye la retórica al esclarecimiento de esta tesis? ¿Está ya la palabra escrita llena de «vida», tras haber sido traducida al lenguaje contemporáneo? Si bien es cierto que el texto por sí solo no produce sabiduría, la tarea de arrancar del lenguaje petrificado en letras sus sentidos (Einsichten), que se comunicarán mediante el texto, no se puede llevar a cabo solamente mediante una traducción interpretativa. Para verificar la propiedad (o impropiedad) de lo comprendido, se debe comunicar a otros lo que se ha comprendido. Cuando Gadamer afirma de las definiciones a las que se llega en el Fedro sobre la retórica "real» que deberían coincidir también con la hermenéutica, y explica sobre su objeto que representan una aparición del lenguaje (Spracherscheinung), como todos los fenómenos de la comprensión mutua, del entendimiento y de la incomprensión, aparentemente considera una posibilidad que se halla menos en el arte del entender que en el arte de la exposición del entendimiento. Kant ya llamó la atención sobre la particular problemática de esta modalidad de la comunicación. Para el filósofo alemán la comunicabilidad y plausibilidad de lo comunicado deciden en última instancia si otros pueden ser convencidos de lo que nosotros tenemos por verdadero. Esta problemática se repite en Gadamer una y otra vez. Para Gadamer, la comprensión representa una tarea que el que ha entendido algo debe dominar, para poder probar que lo que 
cree haber entendido, es decir, que considera verdadero, también puede ser reconocido como verdadero por otros. Para ello debe exponer lo que ha comprendido de forma convincente, evidente y plausible, de manera que la persona a quien va dirigida la exposición comprenda algo de lo expuesto. Decisivo en este sentido es el grado de plausibilidad y de verosimilitud que da el orador a su discurso. El que otros se dejen convencer por sus declaraciones depende de que las juzguen dignas de crédito, verdaderas y evidentes. Como lo convincente puede demostrar sólo lo que es certificable inmediatamente, sólo queda la posibilidad de convencer a otros mediante la fuerza del discurso, no para tener razón, sino para enunciar literalmente el estado de cosas tenido por verdadero. La convicción de haber comprendido algo sólo se puede poner a prueba comunicando lo que se ha entendido a otros.

El cometido que Gadamer otorga a la retórica comprende dos tareas: la fundamentación de la tesis de la comprensión como comprensión otra (Andersverstehen), esto es, justificar lo que se ha comprendido de manera nueva y otra, y explicitar esta tesis en el plano de la obra escrita. Para que la interpretación sea algo más y otra cosa que el texto interpretado a fin de hacerlo comprensible, el texto no sólo se traduce al correspondiente lenguaje de la interpretación. Para estar a la altura de esta tarea hay que reconocer en primer lugar las relaciones de sentido (Sinnbezüge) sobre las que reflexiona el intérprete. El acto de comprender depende de un reconocimiento previo a través del cual se consuma la comprensión otra. En la reflexión sobre el reconocimiento (Wiedererkennen) de lo que el autor ha reconocido (Erkennen) se cumple la comprensión del sentido de lo leído, que tiene que justificarse frente al texto y a otras interpretaciones de una manera muy parecida a la actividad de la retórica tal como la describe Gadamer.

$\mathrm{Al}$ preguntarnos qué constelación forma la retórica rehabilitada con la filosofía práctica en la hermenéutica de Gadamer, obtenemos una respuesta cuando tenemos en cuenta qué reflexión es común a la retórica y a la hermenéutica en la tesis básica hermenéutica de la comprensión concebida como comprensión otra. Gadamer ha expuesto esta reflexión en el contexto de la destrucción de la hermenéutica que emplea una metodología moderna: «¿Dónde, si no en la retórica, se podría inscribir la reflexión teórica sobre la comprensión, que desde la más antigua tradición es la única abogada de una exigencia de verdad que defiende lo probable [...] contra la exigencia de certeza y de demostración de la ciencia? Convencer e ilustrar sin ser capaz de proporcionar una prueba es manifies- 
tamente el objetivo y la medida tanto de la comprensión y de la interpretación como del arte de la oratoria y de la persuasión [... ${ }^{25}$. Si la hermenéutica es la abogada de una tal exigencia de verdad, Gadamer es consecuente cuando afirma que la hermenéutica y la filosofía práctica convergen: la hermenéutica filosófica de Gadamer es práctica porque alude a una modalidad del saber de la tradición específica y no objetivable, que no es ni algo continuo ni algo dado inmediatamente, porque la comprensión de esta forma de saber es un acontecimiento que se pone a prueba continuamente, que amplía y corrige las antiguas concepciones y que integra nuevas experiencias, que es dependiente del lenguaje como «interpretación omniabarcante del mundo»" La concepción de Gadamer de la hermenéutica como filosofía práctica se basa en la corrección de un concepto de la retórica difamado y estrecho de miras, en que el problema de la descripción de la relación de la ética y la hermenéutica sigue sin aclararse. Para persuadir a otros de algo de cuya verdad estamos convencidos se necesita una atención bienintencionada por parte de los oyentes, sin la cual éstos apenas mostrarán interés por lo que a nosotros nos parece importante. Este aspecto ha sido infravalorado por Gadamer.

${ }^{25}$ Id., «Rhetorik, Hermeneutik und Ideologiekritik» (1967), GW 2, 232-250, aquí: 236.

${ }^{26}$ Id., «Begriffsgeschichte als Philosophie», op. cit., 79. 